\title{
Synthesis and Properties of Novel Poly(Hexyl-Substituted Lactides) for Pharmaceutical Applications
}

\author{
Thomas Trimaille, Robert Gurny, and Michael Möller
}

\begin{abstract}
Monohexyl-substituted lactide ( $\mathrm{mHLA}$ ) was synthesized by reaction of 2-hydroxyoctanoic acid with 2-bromopropionyl bromide, and polymerized with tin(I) 2-ethylhexanoate (Sn(Oct) ${ }_{2}$ ) or 4-dimethylaminopyridine (DMAP) in the presence of benzyl alcohol by ring-opening polymerization (ROP). Poly(monohexyl-substituted lactide) (PmHLA) of predictable molecular weights and narrow polydispersities were obtained in convenient bulk conditions at $100{ }^{\circ} \mathrm{C}$ within short polymerization times. The polymerizations were well controlled, showing a 'living' character for targeted degrees of polymerization up to $\mathrm{DP}=60$ as evidenced by molecular weight versus conversion studies and ${ }^{1} \mathrm{H}$ NMR end group analysis. The hexyl groups have a strong impact on the glass transition temperature $\left(T_{\mathrm{g}}\right)$, which is low for PmHLA compared to standard poly(D,L-lactide) (PLA). $\mathrm{T}_{\mathrm{g}}$ and zero shear viscosities at $25^{\circ} \mathrm{C}$ can be controlled by the polymer molecular weight, ranging from $-22{ }^{\circ} \mathrm{C}$ for $M_{n}=2800 \mathrm{~g} / \mathrm{mol}$ to $-10{ }^{\circ} \mathrm{C}$ for $M_{n}=9100$ $\mathrm{g} / \mathrm{mol}$ and 140 to 4850 Pa.s, respectively. These data are in correspondence with the Fox and Flory equations. The degradation mechanism of the PmHLA polymer in phosphate buffer $\mathrm{pH} 7.4$ at $37^{\circ} \mathrm{C}$ was shown to be similar to that of the standard PLA ('bulk erosion' type), with a slightly higher degradation rate, leading to the non-toxic degradation products lactic acid and 2-hydroxyoctanoic acid. PmHLA has the great potential as an alternative to conventional PLA/PLGA for drug delivery systems. By the hexyl-substitution the biodegradable PLA-ester backbone is conserved but the hydrophobicity is increased in comparison to standard PLA, while a viscous polymer is obtained. This leads to advantageous injectable solvent-free drug delivery systems, in which drugs can easily be incorporated by simple mixing.
\end{abstract}

Keywords: Degradation · Injectable drug delivery system · Polylactides · Ring-opening polymerization

\section{Introduction}

Biocompatible and biodegradable polylactides/glycolides (PLA/PLGA) have received great attention over the last thirty years in the biomedical field as sutures, implants, colloidal drug delivery systems [1][2], and more recently also in tissue repairing and engineering [3][4] and anticancer drug delivery [5][6]. Next to the medical field they are also widely used in the packaging area. As biodegradable 'green polymers' they are preferable to

${ }^{*}$ Correspondence: Dr. M. Möller

School of Pharmaceutical Sciences

Ecole de Pharmacie Genève-Lausanne

University of Geneva

Quai Ernest-Ansermet 30

$\mathrm{CH}-1211$ Geneva 4

Tel.: +4122 3793132

Fax: +4122379 6567

E-Mail: michael.moeller@pharm.unige.ch the commodity polymers currently used [7][8]. There is a crucial need for welldefined polylactide-based materials with advanced properties to fit all the requirements for the different applications. For example, PLA/PLGA homo- and co-polymers synthesized by the well-established ring opening polymerization (ROP) process [9] have a glass transition temperature $\left(\mathrm{T}_{\mathrm{g}}\right)$ limited to a range of only 40-60 ${ }^{\circ} \mathrm{C}$ [10][11], independent of the polymer molecular weight and chemical composition. This combined with interesting mechanical properties makes them suitable in medical applications as biodegradable implants, bone fracture fixation devices, scaffolds for living cells. However for drug delivery purposes, they need to be formulated with organic solvents and administered as solutions or in form of nanoand micro-particles as they cannot be injected on their own. Our strategy for novel PLAs with tailored properties is based on the substitution of a methyl ligand on the lactide monomer by other alkyl substituents [12]. The introduction of alkyl side groups is expected to strongly affect mate- rial properties such as the $\mathrm{T}_{\mathrm{g}}$ and viscosity. For pharmaceutical applications further important properties such as degradation rate and profile or drug encapsulation and release will be modified.

Increasing attention was recently focused on injectable polymers as promising alternatives to emulsions, liposomes or microsphere drug delivery systems [13-15]. Next to other alkyl-substituted lactides we reported the synthesis and characterization of the novel poly(monohexyl-substituted lactide) (PmHLA), which was shown to have a low glass transition temperature $\left(\mathrm{T}_{\mathrm{g}}\right.$ $\left.=-17^{\circ} \mathrm{C}\right)$ compared to a standard PLA $\left(\mathrm{T}_{\mathrm{g}} \stackrel{\mathrm{g}}{=}\right.$ $41^{\circ} \mathrm{C}$ ) with the analogue molecular weight (4500 g/mol) [12]. Based on these initial results this hydrophobic hexyl-substituted polylactide could be favorable and interesting for applications as an injectable PLA drug delivery system comparable to the reported semi-solid hydrophobic poly(ortho esters) [16]. The ring-opening polymerization technique used with its living character and functional end groups gives the opportunity to synthesize various new PLA-based copolymers in combination with the estab- 
lished PLA/PLGA systems. By this different functional PLAs with tailored material properties for biomedical applications can be easily obtained.

We present here a detailed study on the synthesis and controlled ROP of these novel hexyl-substituted polylactides, as well as their physico-chemical properties in terms of $\mathrm{T}_{\mathrm{g}}$ and rheological behavior and degradation kinetics and mechanism.

\section{Materials and Methods}

\section{Materials}

Heptaldehyde, 2-bromopropionyl bromide, and 4-dimethylaminopyridine (DMAP) were purchased from Fluka (Buchs, Switzerland). D,L-lactide from Purac Biochem (The Netherlands) was delivered under vacuum and directly transferred into a glove-box for storage. Tin(II) 2-ethylhexanoate $\left(\mathrm{Sn}(\mathrm{Oct})_{2}\right)$ was purchased from Aldrich (Buchs, Switzerland) and used as received. Benzyl alcohol (Fluka) was successively dried over anhydrous magnesium sulfate and sodium and distilled prior to use. Solvents were dried by standard methods and distilled prior to use.

\section{Monomer Synthesis}

\section{2-Hydroxyoctanoic acid (2)}

To $78 \mathrm{~g} \mathrm{NaHSO}_{3}(0.75 \mathrm{~mol})$ in water $(1$ 1) heptaldehyde (57 g, $0.5 \mathrm{~mol})$ was added under vigorous stirring for $30 \mathrm{~min}$; then a solution of $\mathrm{NaCN}$ (32 $\mathrm{g}, 0.65 \mathrm{~mol})$ in water $(250 \mathrm{ml})$ was added and the mixture was shaken for $15 \mathrm{~min}$. The upper layer upon separation of phases was poured directly into a solution of $40 \mathrm{v} \%$ sulfuric acid $(165 \mathrm{ml})$ and heated at $125^{\circ} \mathrm{C}$ for $3 \mathrm{~h}$, then poured into $6 \mathrm{M} \mathrm{NaOH}(500 \mathrm{ml})$ and stirred for 12 $\mathrm{h}$. The alkaline solution was washed with $\mathrm{Et}_{2} \mathrm{O}(2 \times 150 \mathrm{ml})$ then acidified with $2 \mathrm{M}$ $\mathrm{HCl}$ and extracted with $\mathrm{Et}_{2} \mathrm{O}(3 \times 150 \mathrm{ml})$ which was washed with brine $(100 \mathrm{ml})$, dried, and evaporated. Recrystallization from toluene gave $47 \mathrm{~g}(59 \%)$ of pure product; ${ }^{1} \mathrm{H}$ NMR $\left(500 \mathrm{MHz}, \mathrm{CDCl}_{3}\right): \delta 4.28$ (dd, 1H), 1.65-1.9 (br m, 2H), 1.4-1.5 (br m, $2 \mathrm{H}), 1.25-1.35$ (br m, 6H), 0.89 (t, 3H). ${ }^{13} \mathrm{C}$ NMR $\left(500 \mathrm{MHz}, \mathrm{CDCl}_{3}\right.$ ): $\delta 180.00,70.3$, $34.11,31.59$, 28.89, 24.67, 22.53, 14.00 .

\section{3-Methyl-6-hexyl-1,4-dioxane-2,5- dione (4) (referred as monohexyl- substituted lactide)}

$10.1 \mathrm{~g}$ 2-hydroxyoctanoic acid (63 $\mathrm{mmol}$ ) and $7.0 \mathrm{ml}$ 2-bromopropionyl bromide $(66 \mathrm{mmol})$ were stirred at $85^{\circ} \mathrm{C}$ under nitrogen for $12 \mathrm{~h} .500 \mathrm{ml}$ acetone and $17.6 \mathrm{ml}$ anhydrous triethylamine (126 mmol) were added to the mixture and the solution was stirred for $3 \mathrm{~h}$ at $60^{\circ} \mathrm{C}$. After filtration of the triethylammonium bromide salts, acetone and triethylamine were distilled off and the resulting mixture was dissolved in $500 \mathrm{ml}$ ethyl acetate/hexane mixture 1:2. After filtration over silica gel the solvents were distilled off, and the remaining crude product was recrystallized from hexane at $-20{ }^{\circ} \mathrm{C}$. Yield: 45\%; ${ }^{1} \mathrm{H}$ NMR $\left(500 \mathrm{MHz}, \mathrm{CDCl}_{3}\right): \delta$ 5.00 (q, 1H), 4.89 (dd, 1H), 1.9-2.15 (br m, $2 \mathrm{H}), 1.70(\mathrm{~d}), 1.66(\mathrm{~d}),(3 \mathrm{H}$, of 2 diastereomers), 1.45-1.65 (br m, 2H), 1.25-1.40 (br $\mathrm{m}, 6 \mathrm{H}), 0.90$ (t, 3H). ${ }^{13} \mathrm{C}$ NMR $(500 \mathrm{MHz}$, $\left.\mathrm{CDCl}_{3}\right): \delta 167.53,166.90 .166 .26,165.87$, $75.80,72.49,72.25,31.92,31.45,31.39$ $30.00,28.73,28.50,24.60,24.29,22.48$, $22.44,17.54,15.83,14.00$.

\section{Polymer Synthesis and Characterization}

Polymerizations were typically run with $2.0 \mathrm{~g}$ of monomer 4 in bulk (hexyl-substituted lactide) or in toluene (D,L-lactide) in the presence of $\mathrm{Sn}(\mathrm{Oct})_{2}$ as catalyst and benzyl alcohol as initiator in equimolar amounts. A reaction flask containing a stirbar was fitted with a septum, flamed under vacuum, and placed into a glove-box where the monomer 4 was filled in. In a typical procedure (for a targeted degree of polymerization [DP] of 30), $2.0 \mathrm{~g}$ monohexyl-substituted lactide (9.34 mmol) were heated for melting and $360 \mu \mathrm{l} \mathrm{Sn}(\mathrm{Oct}){ }_{2}$ stock solution $(0.35 \mathrm{~g} / \mathrm{ml}$ in dry THF) and $160 \mu$ l benzyl alcohol (from a 5-fold diluted stock solution in dry THF $(0.310 \mathrm{mmol}))$ were added under argon atmosphere, and the mixture was heated to $100{ }^{\circ} \mathrm{C}$. The procedure was typically the same for D,L-lactide polymerization except that dry toluene was added to the monomer for solubilization before addition of the catalyst and initiator.

At the desired reaction time the reactions were stopped by adding $10 \mathrm{ml}$ of THF, followed by precipitation in cold methanol and drying at $40{ }^{\circ} \mathrm{C}$ under vacuum. Polymerization conversions and DP were determined by ${ }^{1} \mathrm{H}$ NMR analysis, and molecular weights and polydispersities by gel permeation chromatography.

The ${ }^{1} \mathrm{H}$ NMR spectra were recorded in either deuterated chloroform or acetone$\mathrm{d}_{6}$ with a Bruker spectrometer $(500 \mathrm{MHz})$ Gel permeation chromatography (GPC) was carried out on a Waters chromatographer, mounted with Styragel HR 1-4 columns (Waters) and connected to a Waters 410 differential refractometer. THF was the continuous phase and polystyrenes of known molecular weights: 500, 2630, 5970, 9100, 37900, $96400 \mathrm{~g} / \mathrm{mol}$ (Tosoh Corporation) were used as calibration standards.

\section{Thermal Analysis}

Glass transition temperatures $\left(\mathrm{T}_{\mathrm{g}}\right)$ were measured with a differential scanning calorimeter (SSC/5200, Seiko Instruments). Heating was performed at a flow rate of 10 ${ }^{\circ} \mathrm{C} / \mathrm{min}$ and the temperature was calibrated with an indium standard.

\section{Viscosity Determination}

Viscosities were determined using a Bohlin controlled stress rheometer with a parallel plate PU 20 device (Bohlin Rheology $\mathrm{GmbH}$, Mühlacker, Germany). A stress viscosity test (rotation) was applied to the samples which were placed on the stationary lower plate. The temperature was fixed at $25^{\circ} \mathrm{C}$ or $37^{\circ} \mathrm{C}$ during the test with a Bohlin Extended Temperature Option (ETO). Shear rates ranging from 0.1 to $400 \mathrm{~s}^{-1}$ were used for determination. For all samples an integration time of $20 \mathrm{~s}$ and a delay time of $20 \mathrm{~s}$ were used.

\section{Degradation Studies}

$40 \mathrm{mg}$ of polymer were placed into flasks and gently heated to be above the $T_{g}$ of the polymers. $5 \mathrm{ml}$ of $0.1 \mathrm{M}$ phosphate buffer $\mathrm{pH} 7.4$ were then added and the flasks slowly agitated at the adequate temperature. At predetermined times polymers were collected, rinsed with milli-Q water and dried to constant weight prior to determination of mass loss and average molecular weight.

Mass loss $(M L \%)$ was evaluated by gravimetric analysis and calculated from:

$$
M L \%=\frac{100\left(W_{0}-W_{t}\right)}{W_{0}}
$$

where $W_{0}$ and $W_{t}$ are the initial weight and residual weight of the dry polymer at time $t$.

Molecular weights were determined by GPC by dissolving the polymer in THF as described above.

\section{Results and Discussion}

\section{Monomer Synthesis and Controlled ROP}

In our previous work we reported the synthesis and ring-opening polymerization of novel alkyl-substituted lactide monomers for the design of new tailored polylactide materials [12]. Here we focus on the poly(monohexyl-substituted lactide) (PmHLA, 5) which was obtained by the synthesis pathway presented in Scheme 1. The synthesis of the new monohexyl-substituted lactide (mHLA, 4) is based on a 'two step one pot' reaction of 2-hydroxyoctanoic acid (2), easily synthesized in large scale from heptanal (1), with 2-bromopropionyl bromide leading to an intermediate ester 3, which undergoes ring closure after changing to basic reaction conditions with triethylamine. This latter intramolecular cyclization is found to be the limiting step of the process with a yield of $45 \%$, despite the dropwise addition of the intermediate 3 into the very dilute basic solution to favor 


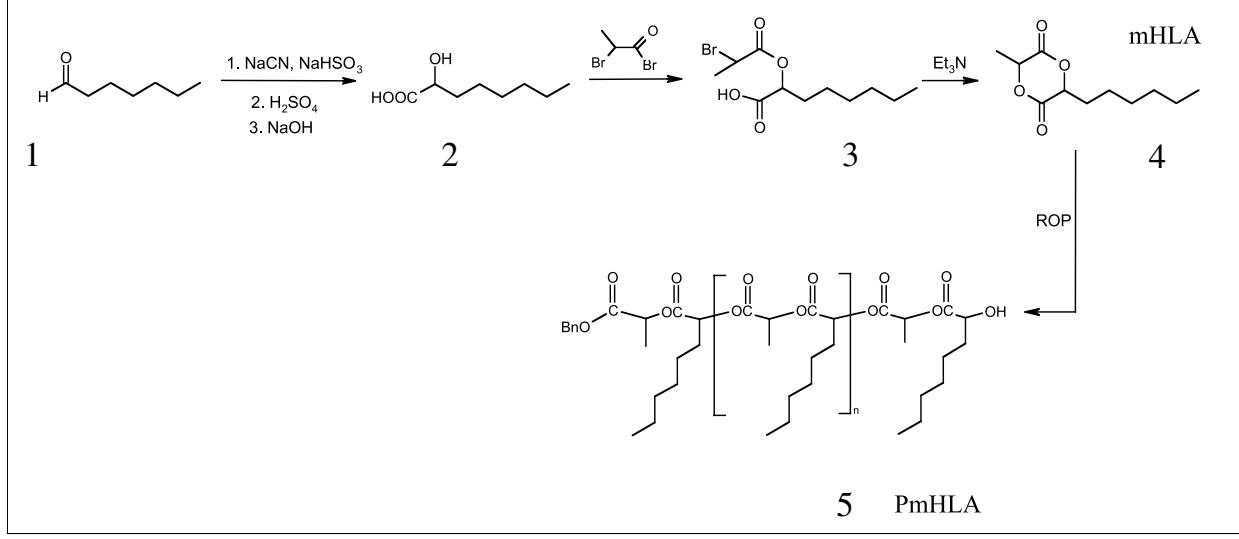

Scheme 1. Synthesis of mHLA monomer (4) from heptanal and ROP to PmHLA (5)

Table 1. ROP of mHLA (4) with $\mathrm{Sn}(\mathrm{Oct})_{2}$ and DMAP at $100^{\circ} \mathrm{C}$

\begin{tabular}{|c|c|c|c|c|c|c|c|}
\hline \multirow{2}{*}{ Catalyst } & \multirow{2}{*}{ Catalyst/BnOH } & \multirow{2}{*}{ Time [h] } & \multirow{2}{*}{ Conversion } & \multicolumn{2}{|c|}{ DP } & \multirow{2}{*}{$\begin{array}{c}M_{n} \\
{[\mathrm{~g} / \mathrm{mol}]}\end{array}$} & \multirow{2}{*}{$\mathrm{M}_{\mathrm{w}} / \mathrm{M}_{\mathrm{n}}$} \\
\hline & & & & Targeted & Measured $^{a}$ & & \\
\hline $\mathrm{Sn}(\mathrm{Oct})_{2}$ & 1 & 4 & 95 & 45 & 39 & 7500 & 1.25 \\
\hline DMAP & 2 & 4 & 82 & 45 & 35 & 7100 & 1.15 \\
\hline
\end{tabular}

aDetermined by ${ }^{1} \mathrm{H}$ NMR on the precipitated polymer using signals of the benzyl protons of the benzyl ester end groups

the ring closure. After recrystallization the mHLA (4) was obtained as a mixture of the two diastereomers (ratio 2:1) which can be easily separated by gel chromatography. This offers interesting perspectives for the properties of the hexyl-substituted polylactides obtained from the diastereomerically pure monomers by ROP, considering the great impact of the stereochemistry on the physico-chemical characteristics of the polymer materials [17]. In the present work we investigated the diastereomeric mixture of the monomer for comparison of the obtained polymer properties with those of the amorphous poly(D,L-lactide).

ROP of the mHLA were carried out in convenient bulk conditions at $100{ }^{\circ} \mathrm{C}$ with two catalysts, $\mathrm{Sn}(\mathrm{Oct})_{2}$ or DMAP 1 and 2 (respectively equiv. to the initiator), in the presence of benzyl alcohol as initiator. Benzyl alcohol was chosen for its suitability to be cleaved off with $\mathrm{H}_{2} / \mathrm{Pd}$ setting free the reactive carboxylic acid end group on the PLA polymer chain for possible further functionalizations. The degree of polymerization (DP), which can be controlled by adjusting the ratio of [monomer]/[BnOH], was targeted at 45 to yield a polymer of about 8000 g/mol molecular weight. Predictable molecular weights and narrow polydispersities were obtained for both catalysts (Table 1). For the same polymerization time of $4 \mathrm{~h}$, the conversion obtained for $\mathrm{Sn}(\mathrm{Oct})_{2}$ catalyst $(95 \%)$ was slightly higher than that observed for DMAP (82\%), even when this latter was used in higher amounts up to 2 equiv. to initiator. Thus the classical $\mathrm{Sn}(\mathrm{Oct})_{2}$ catalyst was selected for the PmHLA synthesis, having the further advantage of being already FDA approved [18]. Studies on the ROP kinetics of the mHLA with this catalyst were performed in terms of molecular weight versus conversion (Fig. 1). For a targeted DP of 45, a linear function was obtained showing that the polymerization is well controlled and of a 'living character'. A typical ${ }^{1} \mathrm{H}$ NMR spectrum of the PmHLA after purification by precipitation in methanol is presented in Fig. 2 and is consistent with this 'living character' of the ROP with the presence of both signals of the benzylester and $\mathrm{CHOH}$ end groups, which confirms the initiation of the ROP by the alcoholate active species. The same studies were performed with the DMAP catalyst and showed the same 'living' behavior. For a high DP of 120, a loss in the control began

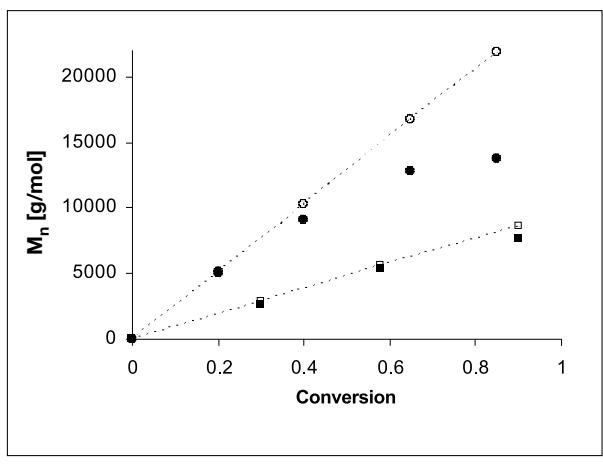

Fig. 1. Molecular weight versus conversion for the ROP of the monohexyl-substituted lactide mHLA at $100{ }^{\circ} \mathrm{C}$ in bulk, with targeted DP of 45 (घ: experimental; $\square$ : expected) and 120 ( $\bullet$ : experimental; $\bigcirc$ : expected) ([BnOH]/[Sn(Oct $\left.)_{2}\right]$ $=1$ )

to occur for conversions higher than $50 \%$ (Fig. 1). This is probably due to the increasing viscosity of the bulk reaction mixture, increasing transesterification side reactions rather than the polymer chain growth via the active polymer end group.

In Fig. 3 the actual and expected molecular weights for different targeted DPs are reported. The obtained molecular weights correspond to the theoretically expected ones up to a DP $=60$. For higher molecular weights a loss in the control of polymerization of mHLA (a) compared to that of D,L-lactide (b) appears. Here a better control can be achieved by changing the reaction conditions. However for the purpose of the desired pharmaceutical applications, this range of controlled polymer molecular weight from 2500 to $10000 \mathrm{~g} /$ $\mathrm{mol}($ e.g. $\mathrm{DP}=10$ to 50$)$ is quite satisfactory since rather low viscosities and reasonable degradation times will be required for the potential use as injectable systems. For our further investigations PmHLAs of different DPs up to 60 (Mn from 2800 to 9100 $\mathrm{g} / \mathrm{mol}$ ) were then prepared with very good control and quite narrow polydispersities $\left(\mathrm{M}_{\mathrm{w}} / \mathrm{M}_{\mathrm{n}} \sim 1.19-1.35\right)$ in bulk conditions at $100^{\mathrm{W}} \mathrm{C}$ ( (Table 2) by targeting the adequate DP and adjusting the polymerization times.

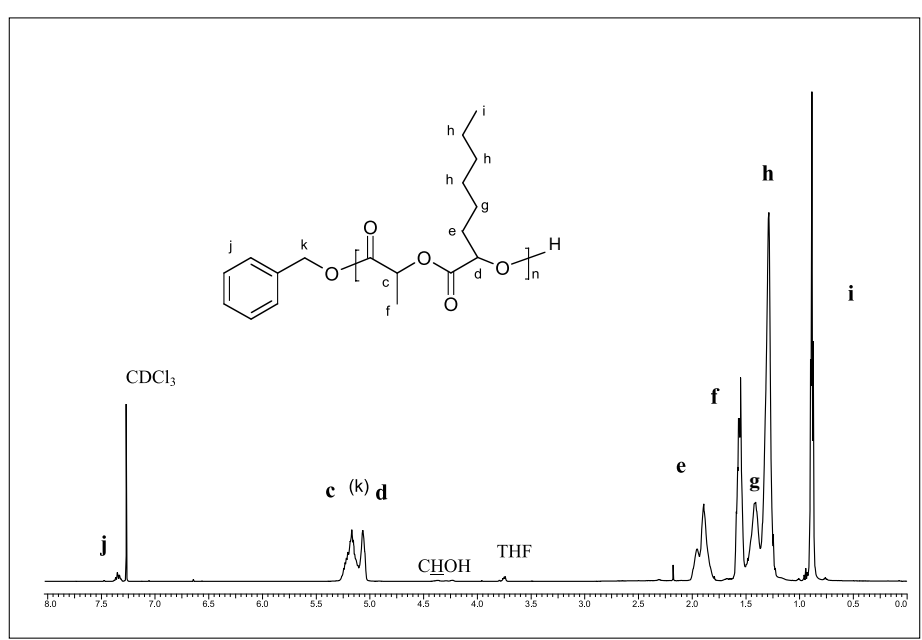

Fig. 2. ${ }^{1} \mathrm{H}$ NMR spectrum of the poly(monohexyl substituted lactide) in $\mathrm{CDCl}_{3}$ 


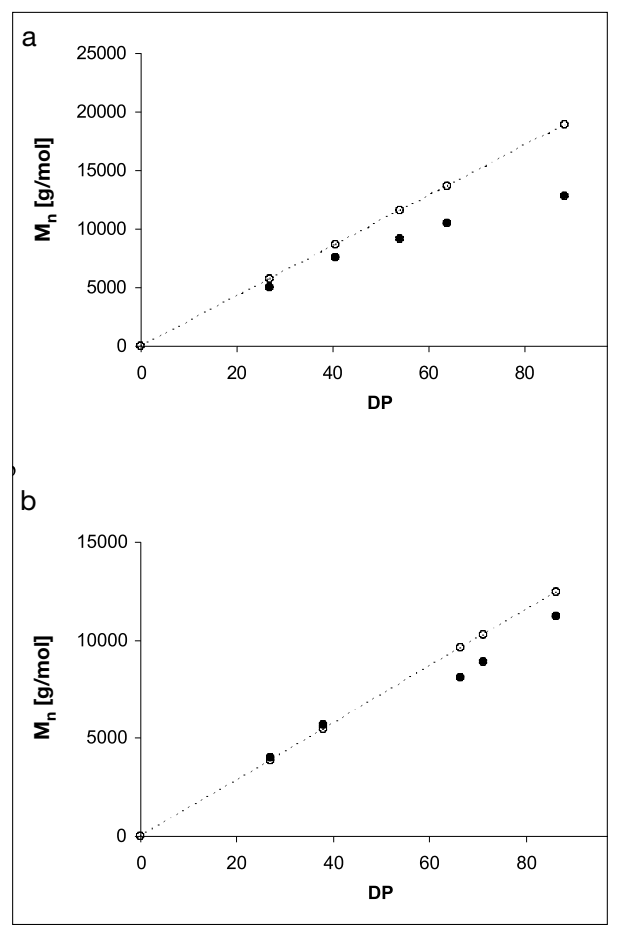

Fig. 3. Control of the ROP of monohexylsubstituted lactide (a) and D,L-lactide (b) performed in bulk or toluene ([monomer]/[BnOH] $=$ targeted $\left.\mathrm{DP},[\mathrm{BnOH}] /\left[\mathrm{Sn}(\mathrm{Oct})_{2}\right]=1\right)$.

For the PmHLA of the lowest $\mathrm{M}_{\mathrm{n}}$ of 2800 $\mathrm{g} / \mathrm{mol}$, the highest polydispersity was observed $\left(\mathrm{M}_{\mathrm{w}} / \mathrm{M}_{\mathrm{n}}=1.35\right)$. Indeed the conversion was rapidly complete for this low targeted DP, and then side transesterification reactions began to occur. Here the polymerization time can be shortened to improve the molecular weight distribution. Standard PLA of about $7500 \mathrm{~g} / \mathrm{mol}$ was prepared under comparable reaction conditions as a control. A polymerization time of $1.5 \mathrm{~h}$ was sufficient to obtain a conversion of about $90 \%$ whereas longer times were required for ROP of the hexyl-substituted lactide due to the steric hindrance of the hexyl side groups, e.g. $2 \mathrm{~h}$ for the analog PmHLA of $7500 \mathrm{~g} / \mathrm{mol}$.

\section{Polymer Physical Properties}

Polymer material properties were particularly investigated in terms of glass transition temperatures $\left(\mathrm{T}_{\mathrm{g}}\right)$ and melt viscosity, two important parameters for the evaluation of the 'injectability' of the material. The $\mathrm{T}_{\mathrm{g}}$ varied from -22.5 to $-10{ }^{\circ} \mathrm{C}$ in the range of the investigated molecular weights (Table 2). The values of the $T_{g}$ as a function of $M_{n}$ fit quite well the Fox-Flory Eqn., as shown in Fig. 4 by the plot of $T_{g}$ as a function of the reciprocal $M_{n}$. For the same $M_{n}$ of about 7500 , PmHLA and PLA have radically different $\mathrm{T}_{\mathrm{g}}$ values with $-12^{\circ} \mathrm{C}$ for PmHLA and $40^{\circ} \mathrm{C}$ for PLA. The impact of the flexible hexyl groups on the glass transition temperature and other physical properties in comparison to stan- dard PLA are obvious. Due to their low $\mathrm{T}_{\mathrm{g}}$ the poly(hexyl-substituted lactides) are in a rubber viscous state at room temperature. For envisioned medical applications by injection the viscosity for these polymers can be controlled by choosing the appropriate molecular weight. In Table 2 the zero shear viscosity values (e.g. in the Newtonian domain) at 25 ${ }^{\circ} \mathrm{C}$ are presented. Here for all the molecular weights PmHLA typically behaved like a Newtonian fluid for a shear rate ranging from 0.1 to $10 \mathrm{~s}^{-1}$ with a constant viscosity. A shear thinning behavior was observed above this value as it is known for many polymers [19]. The zero shear viscosity varied from 140 to $4850 \mathrm{~Pa}$.s at $25^{\circ} \mathrm{C}$ and from 45 to $720 \mathrm{~Pa} . \mathrm{s}$ at $37^{\circ} \mathrm{C}$ by increasing the molecular weight $M_{n}$ from 2800 to $9100 \mathrm{~g} / \mathrm{mol}$. As shown in Fig. 5, the variation of the PmHLA zero shear viscosity with $\mathrm{M}_{\mathrm{w}}$ (in $\log -\log$ scale) followed the Fox and Loshaek theory [20] with a coefficient slope $\alpha \approx 3.2$ independent of the temperature used, suggesting an entanglement point $\mathrm{M}_{\mathrm{c}}$ of the polymer inferior to $\mathrm{M}_{\mathrm{w}}=3700 \mathrm{~g} / \mathrm{mol}$ and an interpenetration of the PmHLA chains [21]. In conclusion the physical properties or the 'injectability' of the hexyl substituted polylactides can be modulated and fine-tuned by varying the molecular weight of these polylactides. Moreover they can be very well predicted from the already well-established calculation models.

\section{Degradation Studies}

For the purpose of injectable drug delivery systems the degradability of the new poly(hexyl-substituted lactide) was investigated. Due to the hexyl side groups this new polylactide is much more hydrophobic than a comparable standard PLA and causes differences to the degradation of PLA. The degradation mechanism of PmHLA and PLA of comparable molecular weights was investigated in terms of molecular weight and weight loss as a function of time in phosphate buffer $\mathrm{pH} 7.4$ at $37^{\circ} \mathrm{C}$. The results are shown in Fig. 6 for PmHLA and PLA of comparable molecular weights of

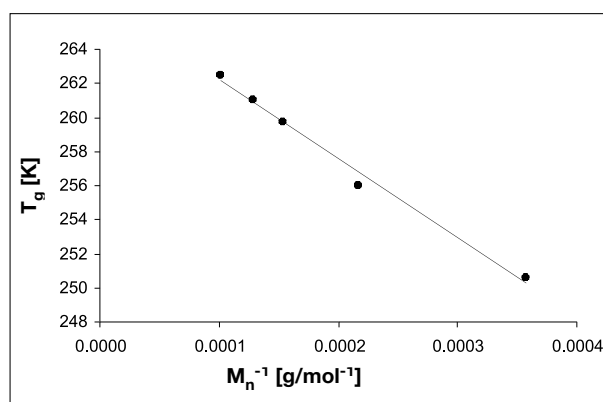

Fig. 4. PmHLA glass transition temperature $\left(T_{g}\right)$ as a function of the reciprocal molecular weight $\left(\mathrm{M}_{\mathrm{n}}^{-1}\right)$

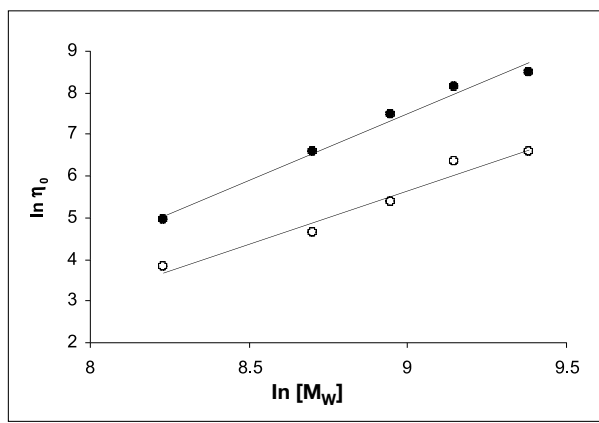

Fig. 5. PmHLA zero shear viscosity $\left(\eta_{0}\right)$ at 37 ${ }^{\circ} \mathrm{C}(\mathrm{O})$ and $25^{\circ} \mathrm{C}(\bullet)$ as a function of the weight average molecular weight $\left(\mathrm{M}_{\mathrm{w}}\right)$

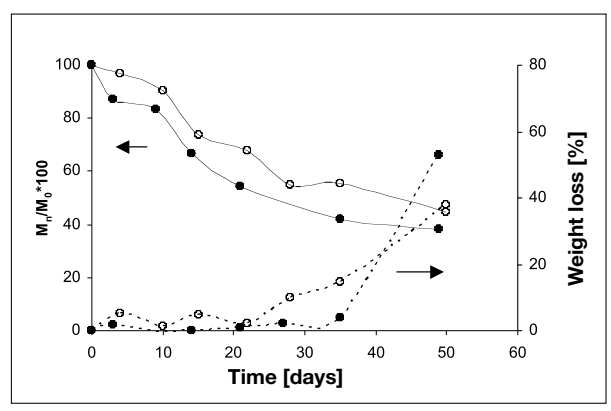

Fig. 6. Molecular weight decrease and weight loss of PmHLA (5) (•) and PLA (O) of $7500 \mathrm{~g} / \mathrm{mol}$ at $37^{\circ} \mathrm{C}$ in phosphate buffer $\mathrm{pH} 7.4$

Table 2. Synthesis of PmHLA (5) of different molecular weights (ROP at $100{ }^{\circ} \mathrm{C}$ ) and their materials properties

\begin{tabular}{|c|c|c|c|c|c|c|c|c|c|}
\hline \multirow{2}{*}{ Monomer } & \multirow{2}{*}{$\begin{array}{l}\text { ROP } \\
\text { solvent }\end{array}$} & \multirow{2}{*}{$\begin{array}{c}\text { Time } \\
{[\mathrm{h}]}\end{array}$} & \multicolumn{2}{|c|}{ DP } & \multirow{2}{*}{$\begin{array}{c}M_{n} \\
{[g / m o l]}\end{array}$} & \multirow{2}{*}{$\begin{array}{c}M_{w} \\
{[\mathrm{~g} / \mathrm{mol}]}\end{array}$} & \multirow{2}{*}{$M_{w} / M_{n}$} & \multirow{2}{*}{$\begin{array}{c}\mathrm{T}_{\mathrm{g}} \\
{\left[{ }^{\circ} \mathrm{C}\right]}\end{array}$} & \multirow{2}{*}{$\begin{array}{c}\eta_{0}\left[25^{\circ} \mathrm{C}\right] \\
{[\text { Pa.s }]}\end{array}$} \\
\hline & & & Targeted & Measured $^{a}$ & & & & & \\
\hline mHLA & Bulk & 1.5 & 15 & 13 & 2800 & 3750 & 1.35 & -22.4 & 140 \\
\hline mHLA & Bulk & 1.5 & 30 & 26 & 4800 & 6000 & 1.25 & -17 & 715 \\
\hline mHLA & Bulk & 2 & 36 & 33 & 6500 & 7700 & 1.19 & -13.3 & 1750 \\
\hline mHLA & Bulk & 2 & 45 & 40 & 7500 & 9400 & 1.25 & -12 & 3500 \\
\hline mHLA & Bulk & 3 & 60 & 59 & 9100 & 11850 & 1.30 & -10.5 & 4850 \\
\hline D,L-LA & Tol. & 1.5 & 50 & 48 & 7200 & 9200 & 1.28 & 40 & glassy \\
\hline
\end{tabular}

aDetermined by ${ }^{1} \mathrm{H}$ NMR on the precipitated polymer using signals of the benzyl protons of the benzyl ester end groups 
$7500 \mathrm{~g} / \mathrm{mol}$. The molecular weight decrease profile for PmHLA was similar to that of standard PLA. The hexyl groups on the PmHLA could be expected to decrease the rate of hydrolysis of the ester bonds, because of their higher steric hindrance and a possible hydrophobic protection against water and its hydroxyl ions. But in fact the degradation rate was slightly higher for the $\mathrm{PmH}$ LA, which can be explained by the physical state of the polymers at $37^{\circ} \mathrm{C}$. Here PLA is a glassy rigid polymer $\left(\mathrm{T}_{\mathrm{g}}=40^{\circ} \mathrm{C}\right)$ whereas PmHLA is in a rubber viscous state $\left(\mathrm{T}_{\mathrm{g}}=\right.$ $-12{ }^{\circ} \mathrm{C}$ ). The latter state favors the penetration of the water into the polymer matrix, leading to a higher hydrolization rate, what is also reported by Ye et al. [22]. This influence of the physical state of the polymer on the degradation profile was confirmed by further degradation studies performed at 60 ${ }^{\circ} \mathrm{C}$, a temperature which is above the $\mathrm{T}_{\mathrm{g}}$ of both polymers [19]. As expected the degradation rates strongly increased, but now PmHLA degraded slower than PLA. At 60 ${ }^{\circ} \mathrm{C}$ PmHLA and PLA are both in a rubber state, and thus the slower degradation for PmHLA could only be attributed to the presence and influence of the hydrophobic hexyl groups on the polymer.

Following up the degradation over the whole time period of seven weeks the degradation process could be divided into two phases. In the first weeks of degradation no mass loss was observed and the decrease in molecular weight was the most pronounced. In the second phase the onset of the mass loss occurred together with a slower decrease of the molecular weight. This is typical for a 'bulk erosion' mechanism, in which the hydrolysis first occurs in the inner polymer matrix with a random scission of the ester bonds due to water absorption, followed by the diffusion of the small oligomers formed out of the polymer bulk. This was corroborated by the visual aspect of the polymer, which swelled in the first phase of degradation due to the water absorption. Whereas the 'bulk erosion' mechanism is well-known for the poly(D,L-lactide) [23], this mechanism was quite surprising for the hydrophobic PmHLA. Due to the strong hydrophobic effect of the hexyl side groups along the polymer backbone one could expect a 'surface erosion' mechanism, as it is known for the hydrophobic poly(ortho-esters). In fact, for the studied PmHLAs the mono-substitution pattern and the existing number of hexyl side groups on the polylactide backbone do not have a strong enough hydrophobic effect to be water repellent and protect the inner polymer matrix against hydrolization. Finally, it should be pointed out that despite both polymers having a similar degradation profile in terms of molecular weight decrease, the weight loss of PLA occurred earlier than that of PmHLA. This effect is most probably due to the less water- soluble hexyl-substituted degradation residues from the PmHLA, which diffuse less well from the inner polymer matrix into the outer aqueous phase.

As we have demonstrated the viscosity of this novel monohexyl-substituted PLA can be tailored in order to obtain injectable polymers which at the same time show a good degradability profile for controlled drug release. Investigations with different incorporated drugs are in progress and will be presented in the near future.

\section{Conclusion}

We presented here the controlled synthesis and properties of a novel poly(monohexyl-substituted lactide) (PmHLA, (5)). The ROP of the mHLA monomer (4) for targeted DPs up to 60 is well controlled and of a living character as shown by molecular weight versus conversion studies and ${ }^{1} \mathrm{H}$ NMR. The hexyl side groups along the PLA-polymer backbone have a strong impact on the physical properties in terms of glass transition temperature $\left(\mathrm{T}_{\mathrm{g}}\right)$ and viscosity. These values can be easily tailored by adjusting the polymers molecular weight, corresponding with the Fox and Flory laws. The poly(mono hexyl-substituted lactide) (PmHLA, 5) shows low viscosity and is suitable for injectable drug delivery systems. Since these new hydrophobic polylactide based polymers are synthesized by ring-opening polymerization (ROP) a fine-tuning of this parameter can possibly be achieved by adjusting the number of hexyl side groups choosing the appropriate ratio of monohexyl lactideand D,L-lactide monomer for the resulting copolymers. Moreover the functional end groups of these new polymers can be used for adding and building up advanced molecular structures with further functionalities needed for optimized drug delivery systems.

Under physiological conditions the degradation mechanism of PmHLA (5) can be described as 'bulk erosion' and the degradation rate is similar to that of standard PLA. Further investigations on different poly(alkyl-substituted lactides), also in combination of copolymers with established PLA/PLGA polymers in various compositions and macromolecular architectures are currently in progress.

Received: April 18, 2005

[1] J.P. Penning, H. Dijkstra, A.J. Pennings, Polymer 1993, 34, 942.

[2] K.E. Uhrich, S.M. Cannizzaro, R. Langer, K.M. Shakesheff, Chem. Rev. 1999, 99, 3181.

[3] X. Liu, P.X. Ma, Ann. Biomed. Eng. 2004, $32,477$.
[4] U.A. Stock, J.E. Mayer Jr., J. Long Term Eff. Med. Implants 2001, 11, 249.

[5] L. Mu, S.S. Feng, J. Control. Release 2003, 86,33 .

[6] W. Jiang, R.K. Gupta, M.C. Deshpande, S.P. Schwendeman, Adv. Drug Deliv. Rev. 2005, 57, 391.

[7] R.E. Drumright, P.R. Gruber, D.E. Henton, Advanced Materials 2000, 12, 1841.

[8] E.T.H. Vink, K.R. Rabago, D.A. Glassner, P.R. Gruber, Polym Deg. Stab. 2003, 80, 403.

[9] a) O. Dechy-Cabaret, B. Martin-Vaca, D. Bourissou, Chemical Reviews 2004, 104, 6147 ; b) H.R. Kricheldorf, I. Kreiser-Saunders, C. Boettcher, Polymer 1995, 36, 1253; c) G. Schwach, J. Coudane, R. Engel, M. Vert, J. Polym. Sci. Part A: Polym. Chem. 1997, 35, 3431; d) P. Degée, P. Dubois, S. Jacobsen, H.G. Fritz, R. Jérôme, J. Polym. Sci. Part A: Polym. Chem. 1999, 37, 2413; e) M. Ryner, A. Finne, A.C. Albertsson, H.R. Kricheldorf, Macromolecules 2001, 34,7281 .

[10] K. Jamshidi, S.-H. Hyon, Y. Ikada, Polymer 1988, 29, 2229.

[11] M. Vert, P. Christel, F. Chabot, J. Leray, in 'Macromolecular biomaterials', Ed. G.W. Hastings, P. Ducheyne, CRS Press, Boca Raton, 1984, p. 119.

[12] T. Trimaille, M. Möller, R. Gurny, J. Polym. Sci. Part A: Polym. Chem. 2004, 42, 4379.

[13] B. Amsden, A. Hatefi, D. Knight, E. Bravo-Grimaldo, Biomacromolecules 2004, 5 , 637.

[14] A. Hatefi, B. Amsden, J. Control. Rel. 2002, 80,9 .

[15] A. Merkli, J. Heller, C. Tabatabay, R. Gurny, J. Control. Rel. 1994, 29, 105.

[16] K. Schwach-Abdellaoui, A. Monti, J. Barr, J. Heller, R. Gurny, Biomaterials 2001, 22, 1659.

[17] T. Tsuji, F. Horii, S.H. Hyon, Y. Ikada, $M a-$ cromolecules 1991, 24, 2719.

[18] Food Drug Adm. 'Food additives. Resinous and polymeric coatings', Fed Regist 1975; 40 (121) C (23. June 1975) (CA 83:112493h).

[19] T. Trimaille, R. Gurny, M. Möller, J. Biomed. Mat. Res. Part A, submitted.

[20] T.G. Fox, S. Loshaek, J. Appl. Phys. 1955, 26, 1080.

[21] R.S. Porter, J.F. Johnson, Chem. Rev. 1966, $66,1$.

[22] W.P. Ye, F.S. Du, W.H. Jin, J.Y.Yang, Y. Xu, React. Funct. Polym. 1997, 32, 161.

[23] M. Hakkarainen, A.C. Albertsson, S. Karlsson, Polym. Deg. Stab. 1996, 52, 283. 